\title{
Identifying Priorities for Aging Policies in Two Portuguese Communities
}

\section{Maria João Bárrios, Ana Alexandre Fernandes \& António Manuel Fonseca}

To cite this article: Maria João Bárrios, Ana Alexandre Fernandes \& António Manuel Fonseca (2018) Identifying Priorities for Aging Policies in Two Portuguese Communities, Journal of Aging \& Social Policy, 30:5, 458-477, DOI: 10.1080/08959420.2018.1442112

To link to this article: https://doi.org/10.1080/08959420.2018.1442112

Accepted author version posted online: 20

Feb 2018.

Published online: 20 Mar 2018.

Submit your article to this journal $\widetilde{ }$

山ll Article views: 283

Q View related articles ๘

View Crossmark data 


\title{
Identifying Priorities for Aging Policies in Two Portuguese Communities
}

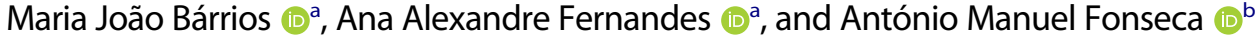

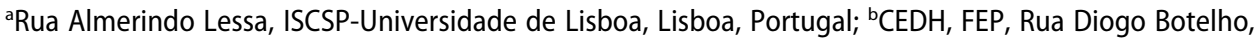 \\ Universidade Católica Portuguesa, Porto, Portugal
}

\begin{abstract}
The aging population has an impact on health, social, and economic issues in regard to individuals, communities, and organizations. The challenge for local policies in response to aging is to create sufficient resources to meet the population's needs, wishes, and rights as people age. Active aging constitutes one of the guiding perspectives on policies. Taking into account the local governance perspective, the Model for Aging Local Policies Analysis (MALPA) was created in order to convert the active aging paradigm into a practical approach, as a technique to evaluate and analyze local aging policies. In this research, the MALPA instrument was applied in two Portuguese communities (Coruche and Oeiras). The objective was to identify the intervention priorities of aging policies in both communities, determining whether the instrument can facilitate the development of proposals for the improvement of local aging policies. It was possible to evaluate the communities and programs, identifying the least appropriate policy actions regarding the intervention priorities. The results allowed us to identify 10 priorities about collaborative governance, involvement of the elderly in the policy-making process, lifelong learning, economic hardship, policies for all ages, isolated vulnerable and fragile groups, intergenerational contacts, safety in all policies, labor opportunities, and conditions and transport network improvement.
\end{abstract}

\section{ARTICLE HISTORY}

Received 14 August 2017

Accepted 29 December 2017

\section{KEYWORDS}

Active aging; local aging policies; aging programs; local governance

\section{Introduction}

In 2016, Portugal had one of the highest proportions of people older than 65 (21.3\%), higher than the EU28 average (19.2\%). It is also one of the countries with a greater proportion of people older than 80 (5.9\%), compared with the EU28 average (5.4\%). The increase in longevity is due to a reduction in mortality and an increase in life expectancy, which in 2014 was 81.3 years in Portugal, higher than the EU28 figure of 80.9 years (at birth). The aging demographic has an impact on several policy sectors and levels (Eurostat, 2016), which have to meet the needs and demands of the elderly, such as cultural, social, health, housing, work, and security issues. 
If the lengthening of life-spans is not proportional to the increase in the number of years of healthy life, the aging population produces health and social problems. This is aggravated if we consider that (1) the probability of health status deterioration, chronic diseases, and comorbidities increases as people age (Gil, 2007) and (2) family changes, such as the reduction of family size, the increase of the number of single parents and single-parent families, the increase in the female activity rate, migratory processes (EspingAndersen, 2009), and less frequent cohabitation between elderly parents and adult children (Fernandes, 2008) make the family less able to take on the burden of their elderly (Capucha, 2012).

For those in good health, the challenge is to keep them active, exercising their rights to civic and social participation. It is also important given that participation in several activities, such as physical, social, and productive, improves life satisfaction (Fonseca, Teixeira, \& Paul, 2011). Researchers, policy makers, and stakeholders seek efficient programs, resources, and devices to meet not only the population's needs but also their wishes, expectations, and rights in order to help people to grow old with wellbeing. This is particularly challenging given that heterogeneity increases as people age, in terms of social, cultural, economic, and health conditions. It means that individuals will reach the more advanced ages with different habits, needs, and aspirations, especially in regard to educational and cultural activities, requiring innovation and livelihood opportunities. Fonseca (2016) addresses this trend in the profile of the "new retirees," resulting from better health and physical condition, higher levels of schooling, and more favorable socioeconomic status. These differentiate them from previous generations. They deal with predictions to be taken into account in the development of policies aimed at improving the well-being of aging people. These population characteristics are manifested in participation in cultural activities, relationships social practices, travel and consumption habits, health care, social valuation, creation of projects for retirement, and living in their own home for as long as possible (Fonseca, 2016).

Research carried out in Portugal has concluded that there are weak conditions of aging, insufficient resources, and inflexible and incipient local interventions, being inflexible and insufficient in responding to the demands of the elderly (Bárrios \& Fernandes, 2014, 2015; Machado, 2004). Please clarify "Research carried out in Portugal has concluded that there are weak conditions of aging, insufficient resources, and inflexible and incipient local interventions, being inflexible and insufficient in responding to the demands of the elderly" Policies that reduce inequalities among elderly social groups are imperative (Almeida, 2009). Being in a situation of permanent austerity, the state is unable to create responses to the aging challenges and diverts the course of action to the social forces that dominate society (Guillemard, 1988; Pierre \& Peters, 2000). Conceptually, this perspective of carrying out policy- 
making processes through partnerships and collaborations between the state and civil society is supported by the governance concept (Bernhard, 2013). It identifies trends in the field of public action related to (2) empowering institutions and actors that are drawn from but also beyond government; (2) blurring of boundaries and responsibilities; (3) power dependence between institutions; (4) autonomous self-governing networks of actors; and (5) use of new tools and techniques to steer and guide (Stoker, 1998, p. 18) for driving collective destination.

The concept was proposed as a process of permanent balance between the needs and the capacities to govern, which is not confined to the interaction between government and society. Consists in the political capacity of groups of actors to act beyond the state, being a process of coordination of actors, social groups and institutions (Le Galès, 2011). We can speak about vertical governance at several levels of action, with actors moving between the public and private, local, regional, national, and supranational (Duran \& Thoenig, 1996). In turn, each of these bodies creates horizontal relations with other sectors of government, public services, private companies, nongovernmental organizations (NGOs), and interest groups (horizontal governance; Stoker, 2011).

Local governance has a special focus and appears as a privileged concept for producing responses which aim to meet the aging challenges. Local organizations (including government groups, NGOs, local enterprises, community associations, and security institutions) play a key role in producing aging policies, due to their proximity to people's lives. The concept of local governance also recognizes the role of several local actors in the creation of integrated policies, depending on the population and territorial context.

The World Health Organization (WHO) proposal of active aging can be considered a potential guide for local interventions and as a multidimensional paradigm, defined as "the process of optimizing opportunities for health, participation, and security in order to enhance quality of life as people age" (WHO, 2002, p. 12). The active aging approach has fulfilled the agreement of the European Commission and Organisation for Economic Cooperation and Development and respects human rights established by the United Nations. However, it creates a challenge for policy makers in regard to its applicability in practice.

In order to convert the active aging paradigm into a practical approach, Bárrios (2017) has created the Model for Aging Local Policies Analysis (MALPA). It is a research instrument that takes into account the local governance perspective and is capable of being used by researchers, policy makers, and stakeholders as a technique to evaluate and analyze local policies and resources available for the elderly. The instrument was submitted to content and building validation, using the Delphi technique, by a multidisciplinary expert group. 
MALPA comprises 10 intervention categories able to include the different programs that can be produced at local level-social, environment, physical activity, culture, education, housing, health, safety, work, and transportation -and 5 analysis dimensions, divided into one or more indicators, selected according to the strength of the scientific evidence of the multidisciplinary paradigm of active aging: (1) active aging pillars: health, participation, and safety; (2) social characteristic: inclusive and intergenerational; (3) collaborative governance: state and local governance, local governance and third sector, and public and private organizations; (4) policy-making process: business consultation of beneficiaries and health or functionality problems; and (5) evaluation: reaching the objectives.

The model has a score calculation system. Each program can be evaluated individually by calculating the program score. On the other hand, a set of aging programs of an institution, organization, or local governance of one or more communities can be evaluated through the calculation of category score, dimension score, indicator score, or total score. The scores range from 1 to 5 , with 1 being the antithesis of active aging, 2 being not suitable for active aging, 3 requiring adaptation to active aging, 4 being in accordance with active aging, and 5 being totally in agreement with active aging. Bárrios (2017) has recognized that the evaluation and analysis of aging policies face difficulties due to the inherent complexity concerning the heterogeneity in the operationalization of the model, taking into account the range of possible applicators with different configurations and functions.

Given the demographic imperative of aging societies and the need for effective aging policies to create efficient solutions and/or ensure that the existing resources are adequate to meet the population's needs, local communities must analyze their programs, identifying good practices and policies that require innovation and improvement. The main goal of this research is to identify the intervention priorities of aging policies in two different Portuguese communities in terms of sociodemographic and economic points of view, through the application of MALPA. At the same time, we propose to test the MALPA instrument in order to develop an understanding of whether it facilitates the development of suggestions and guidelines for the improvement of local aging policies.

\section{The selected municipalities}

Two communities were selected for study, corresponding to the Portuguese municipalities: Coruche and Oeiras. The selection related to collaboration availability, sociodemographic and economic diversity, and a range of living conditions: Coruche is a territory with rural characteristics and Oeiras is a territory with urban characteristics. Thus, the research integrated two municipalities with differentiated characteristics in terms of territorial, 
sociocultural, economic, and population profile levels. We are concerned mainly with communities in the geographical sense and the lifestyles of the population, considering that many aspects of the environment of a given community are important for the older adults, both urban and rural (Menec, Means, Keating, Parkhurst, \& Eales, 2011).

Coruche and Oeiras presented different characteristics in terms of territorial, social, economic, and population profiles. It is known that many aspects of a community environment are important for older urban and rural adults (Menec et al., 2011). We do not intend to go into the definitions of urban and rural territories, but we have a particular interest in community geographical sense and population lifestyles. As a whole, the selected municipalities provide a sample with great diversity and expression.

Coruche has a low population density $\left(1,788\right.$ inhabitants $\left./ \mathrm{km}^{2}\right)$, and $29.4 \%$ of the population are 65 years or older. It represents one of the areas of Portugal with the oldest population, with an aging index (247.6) higher than the country's average (128.6). Most people live in small clusters and are predominantly linked to the agricultural sector, with an illiteracy rate of $14.59 \%$. On the other hand, Oeiras is one of the most populous Portuguese villages, with a high population density $\left(37,548\right.$ inhabitants $\left./ \mathrm{km}^{2}\right)$ and with $19.2 \%$ of the population being 65 years or older. It has a lower aging index (125) and urban characteristics and the illiteracy rate is only $2.22 \%$ (INE, 2011).

\section{Methods}

The study involved two distinct moments. Initially, we conducted a survey in both municipalities, collecting detailed information about local aging programs from the local government, NGOs, health centers, social and private institutions and companies, local associations, security forces, and policing. After that, the qualitative methodology resorted to documentary analysis of programs, projects, resources, practices, and initiatives-clarifying its operation, objectives, target population, and responsible entity. In a second moment, the MALPA instrument was applied to the local programs identified in Coruche and Oeiras through its quantitative methodology of scores calculation. Each program was introduced in the category of major intervention and analyzed in all indicators that constitute the MALPA, on a scale of 1 to 5, according to the model instructions (Bárrios, 2017) synthesized in Table 1.

MALPA was applied to the collected programs and we can interpret the information at macro, meso, and micro levels in order to produce implications for practice/policies. At a macro level we can calculate the total score of each organization or community. At a meso level, the intervention priorities are the categories, and dimensions and indicators with the lowest score were identified. 


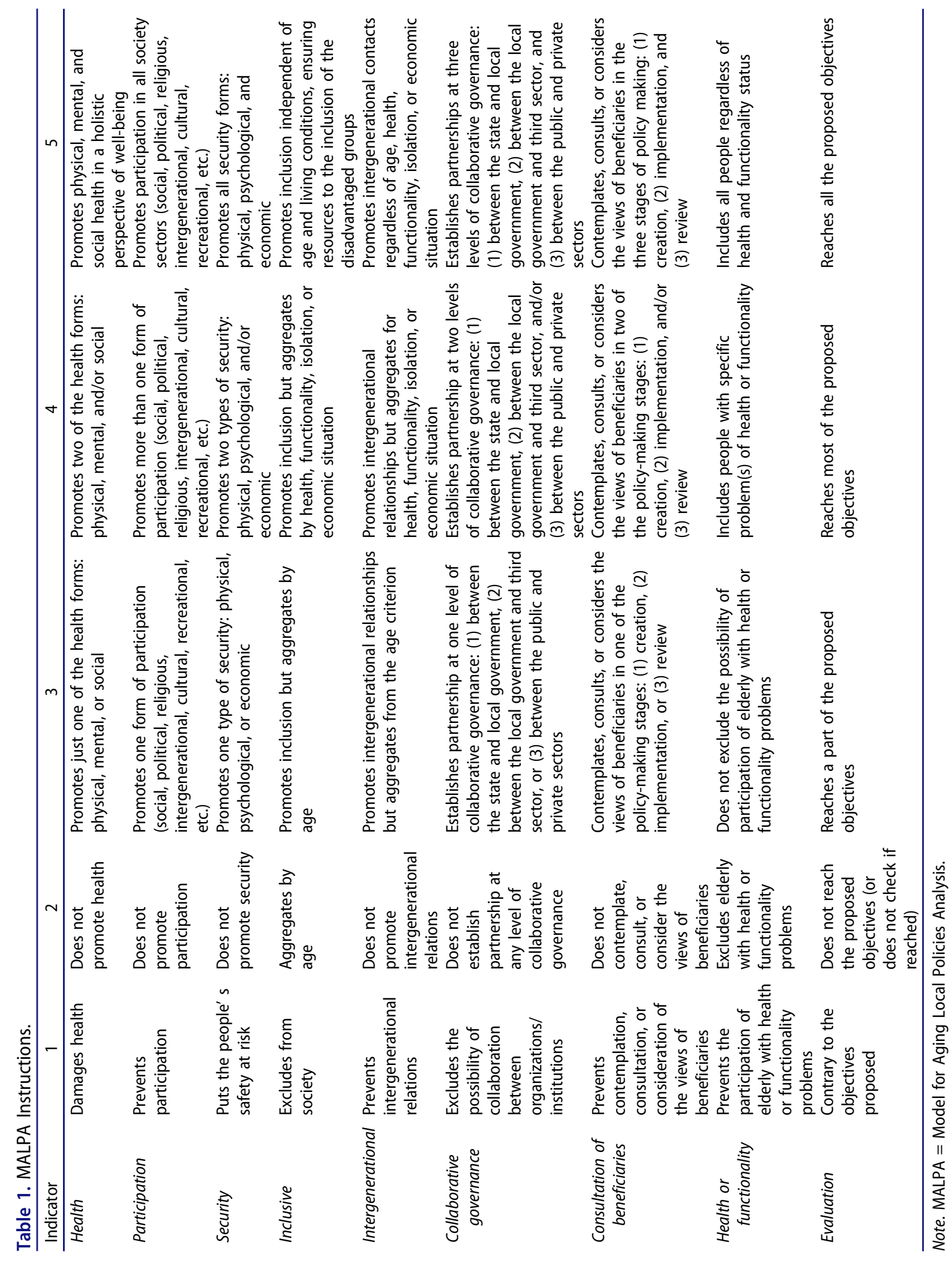


At a micro level, the programs with the lowest scores are far from the active aging perspective and therefore are the intervention priorities. The categorization of the policy priorities is derived from the indicators previously established by the instrument and can be considered by stakeholders of both municipalities.

\section{Findings}

\section{MALPA application}

Coruche has a total score of 3.6 and Oeiras 3.8, both positive on a scale of 1 to 2155, with a rank between 3 (requires adaptation to active aging) and 4 (in accordance with active aging) (Table 2 and 3). As can be seen in Table 4, the intervention category that has the lowest score in Coruche was culture (3.4) and in Oeiras was education (3.4). We have analyzed 37 programs in Coruche and 42 programs in Oeiras (Table 5). The lowest scores in each category are identified as intervention priorities.

\section{Discussion}

\section{Macro and meso levels: Dimensions, indicators, and categories}

The collaborative governance dimension had the lowest score both in Coruche (2.8) and Oeiras (3), requiring our further reflection. It means that the analyzed programs are not benefiting from collaborative actions between the various actors in the communities. Resources are not being fully optimized, and there is weak involvement of private companies in collaborative processes between local government and civil society. Barbosa, Feio, Fernandes, and Thorslund (2016) concluded that, in Portugal, although social protection is based on the private and nonprofit sectors, the local level does not include private companies in stakeholders' meeting and governance processes. The local governance model operates on vertical coordination. Everingham, Warburton, Cuthill, and Bartlett (2012) noted that horizontal approaches would avoid or correct the overlapping responses, leveraging the creation of innovative and nonexistent measures. The efforts at articulation among public, private, and community actors are a way to improve local aging policies in terms of the design and implementation of programs and services. However, there is a research shortage on the impact of different forms of collaboration as well as on the processes capable of enhancing success (Everingham et al., 2012). We can find barriers such as hierarchical functioning of the entities involved, lack of knowledge about the potentialities and benefits, lack of communication among the different actors, and inertia regarding change.

Priority 1 is to invest in partnerships among local authorities, private companies, and civil society organizations and to identify the obstacles to 

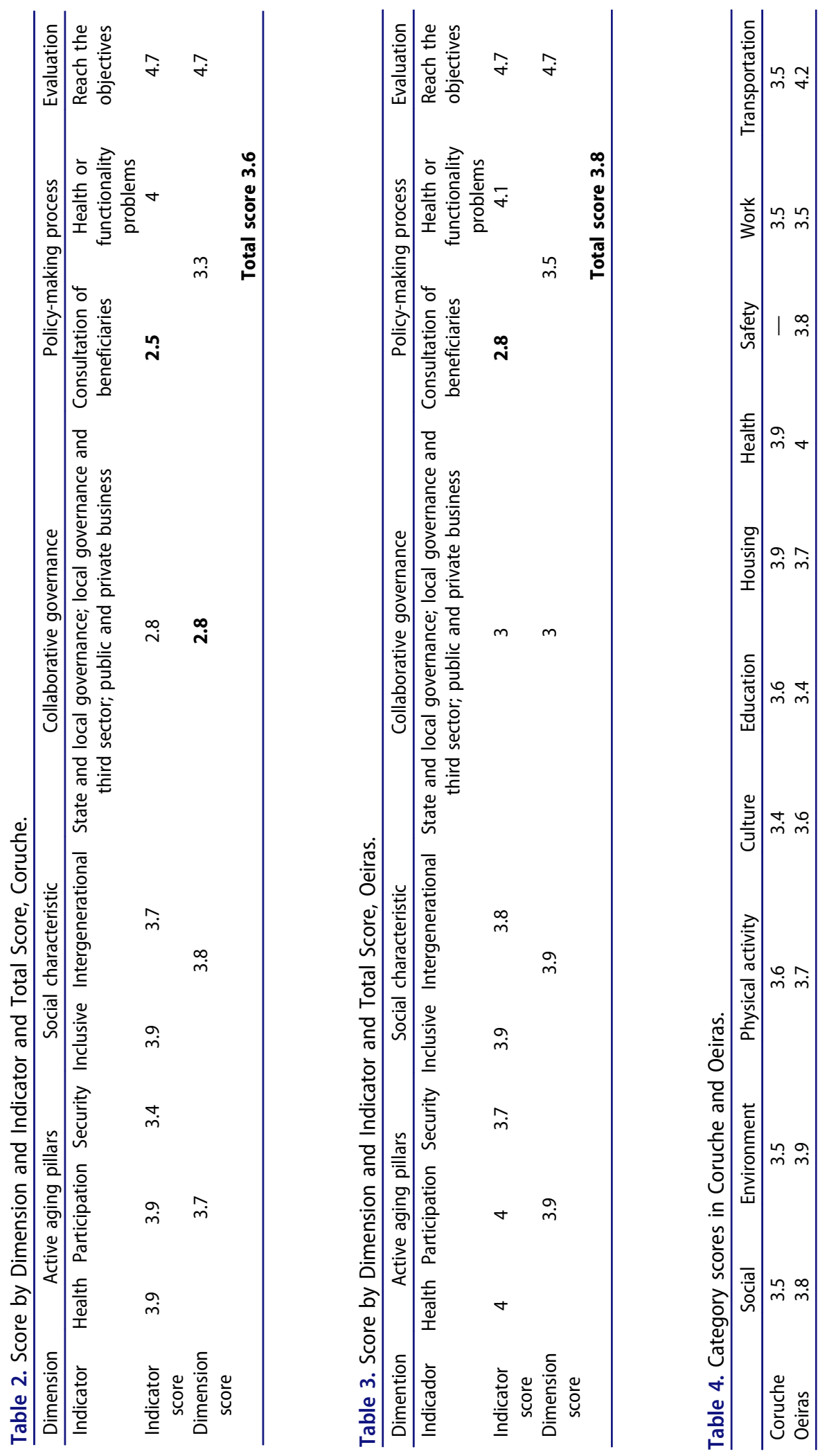


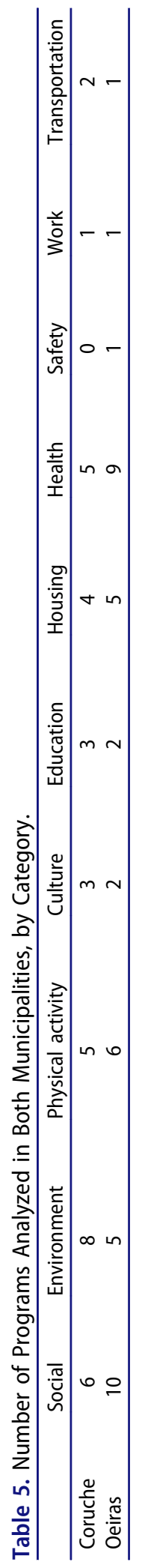


collaboration in each community, through a context scrutiny, listening to the actors responsible for decision-making processes. Understanding these obstacles requires a thorough examination of the context of each community. Knowledge of perceptions of local and central stakeholders will help to understand how decisions are made.

Similar results were found in the indicator with the lowest score: the consultation of beneficiaries, which reached the lowest value in both municipalities: 2.5 in Coruche and 2.8 in Oeiras (Tables 3 and 4). The elderly's views can be contemplated, consulted, or considered in the three stages of the policy-making process: creation, implementation, and review. This participatory approach promotes benefits for users, improves policies, and is also in line with the active aging strategy. The involvement of the elderly in the process of making aging policies can develop positive opportunities for them, such as participating in community groups, volunteering, and organizing activities. However, the participatory approaches require the guarantee of favorable conditions for their development and effectiveness. Popescu (2013) raises specific issues, such as (1) whether political representatives are prepared to accept the direct involvement of citizens, (2) whether policy makers are willing to share responsibilities, and (3) whether community members are aware of the importance of these commitments. The community-based approaches also require encouraging older citizens to take personal responsibility for success. They will press individuals, giving them a direct stake in the programs and changing their own habits in ways that could make a key contribution to overall effectiveness (Popescu, 2013, p. 98). The citizencentered view is a characteristic of democratic politics, and the elderly's position in this space is changing. As the proportion of elderly citizens increases, they become an increasingly important electoral force that is recognized by governments, particularly since voter turnout is higher in the older age groups (Goerres, 2007).

Priority 2 is to engage the elderly in the process of making aging policies; to make public, private, and civil society members aware about the elderly's potentialities; to identify the obstacles to the involvement of the elderly in each territorial unit; and to analyze perceptions of political and institutional representatives about this approach to participation.

We saw that the categories with the lowest scores were culture and education. In fact, cultural and educational activities are directed, in particular, toward the postretirement period or last life stage and do not respect the lifelong learning principle. This perspective contradicts the active aging concept, taking into account that the life cycle is no longer structured in three stages (education, work, and retirement) but is intermittent and flexible. These issues are also related to the need for measures that adopt actions to develop work skills throughout the working life. The initiatives created specifically for the last phase of life contradict the demands of a flexible life 
cycle and a longer life. The next very old people will have new educational requirements, which raises doubts about the capacity of these activities to supply their aspirations.

Priority 3 is to develop cultural and educational resources through a lifelong and transversal path, facilitating autonomous practices. This guideline meets the perspective of active aging and life cycle, with regard to lifelong learning.

\section{Micro level: Aging programs}

In the social category, the programs with the lowest score were the senior card (3.2) in Coruche and the senior card 65+ (3.2) in Oeiras. Both programs are similar and comprise the provision of economic benefits to people aged 65 years and older on several public and private products and services: social resources, health care, and cultural and playful activities. Socioeconomic inequalities have been associated with population aging as adjacent concerns. Aging measures should take them into account, seeking to reduce or eliminate them. Olshansky et al. (2011) call for a social agenda that addresses the economic needs of society, promoting the well-being of disadvantaged and marginalized people. Aging policies must create initiatives and services for the whole population, overcoming the challenges of unfavorable financial situations. According to Lowndes, Pratchett, and Stoker (2006), socioeconomic discrepancies affect participation levels, as individuals with higher incomes are more active. Fitzgerald and Caro (2014) agree, concluding that potential barriers to use of health and social services include cost, information, and a combination of distance and transportation. Senior card programs follow the recommendations of the collaborative governance dimension through partnerships between public and private organizations. However, they have the lowest value in the social category because they are ranked solely in terms of age and do not assess people's real economic conditions, suggesting an association between age and poverty. Although the elderly population includes many poor people, being old does not imply a poor economic condition. Financial challenges settle on all ages and these programs may be excluding a population fragment that is truly economically disadvantaged.

Priority 4 is to dissociate age from economic hardship. Programs oriented to support disadvantaged situations should be focused on real economic capacities, helping the poor of all ages to grow old with well-being.

The environmental programs furthest from the active aging concept were gerontological equipment in Coruche (2.5) and environmental awareness actions in Oeiras (3.7). Gerontological equipment consists of an outdoor gymnasium for physical activity practice for the elderly. Physical activity levels are associated with factors such as availability and proximity to appropriate places and fitness 
equipment at home and in neighborhoods (Sallis, Bauman, \& Pratt, 1998). However, the placement of instruments intended for physical activity practice specifically for the elderly can impose unequal segregation on the population interests. It distances itself from the active aging strategy. Although the instruments are accompanied by instructions, these may not be read or understood by the population with low schooling and are therefore not safe.

Priority 5 is to develop policies for citizens of all ages without segregation and to provide opportunities to improve well-being throughout the life cycle. We acknowledge that environmental awareness actions about education and environmental sustainability are important, since maintaining healthy and clean environments is a responsibility of all citizens. Nevertheless, participation could be expanded, making efforts to amplify the number of participants by establishing partnerships with public and private entities. Furthermore, safety could be improved through initiatives such as providing information on protection against excessive cold and heat, teaching the population about environmental behaviors and risk awareness, and diagnosing air and water quality in housing for the poor. Last, the beneficiaries of environmental awareness actions are only consulted in the implementation phase. In agreement with priority 2 , earlier inclusion of the elderly could adapt the contents of the actions to the population's interests.

The gerontomotricity program (3.4) in Coruche and the 55+ physical activity program (3.4) in Oeiras provide regular physical activity classes of several modalities at the gymnasium, at the swimming pool, and in open air spaces, controlled by specialized technicians. However, they reach the lowest score in the physical activity category, since not all elderly citizens can participate due to lack of transportation or financial capacity. In addition, exclusive programs for the elderly run the risk of removing them from the rest of society by exercising segregation through age. For these reasons, both programs require adaptation. As reported in priority 5, programs should not categorize people by age but instead should be inclusive.

In the cultural sector, the lowest scores corresponded to the senior association ASSECOR (3.3) in Coruche and senior tourism (3.4) in Oeiras. ASSECOR provides opportunities and support for the elderly to remain in mainstream society and socially connected, through organizing cultural events and keeping people busy. Nevertheless, these initiatives are exclusive to the elderly and all the events take place in the urban center. Thus, programs are limited to a minority population: participative, autonomous, without mobility or functionality limitations, and able to move by their own means. Once again, this is in conflict with priority 5 , considering that aging policies, instead of being addressed to a minority cluster, should be easily accessible to the wider public. 
Priority 6 is offering equal opportunities for all, regardless of health condition and irrespective of their social or financial situation. Special attention should also be given to isolated groups and those in a vulnerable and fragile condition. Although the elderly have more time available to travel, according to Eurostat tourism statistics, in 2013, less than half of the European Union population aged 65 and older participated in tourism (47.1\%), compared with $60 \%$ of the population aged 15 years and older. The possibilities for enjoying travel and tourism in old age are related to health issues and income availability (Eurostat, 2016). Among the elderly, health issues play a greater role than financial matters, and there is also a high proportion of the elderly who have no motivation to travel (Eurostat, 2015). Senior tourism can provide occasions for those who do not travel spontaneously. However, these events are neither inclusive nor intergenerational, being exclusively for the elderly, and do not guarantee the participation conditions for those most fragile and sick. Here again, priorities 5 and 6 should be applied.

In the education category, intergenerational activities (3.3) constitute the lowest-rated program in Coruche and senior universities (3.3) are lowest-rated in Oeiras. There is a tendency in global society to devalue elders, through the idea that they are incapable, inflexible, and resistant to change; that old age corresponds to a "second childhood"; and that old age is associated with illness, inactivity, depression, irritation, and disability (Fonseca, Duarte, \& Moreira, 2013). Advocates of intergenerational programs believe that these interactions between members of different generations benefit the elderly by increasing feelings of belonging to the community (Manheimer, 1998). Initiatives that promote relationships between generations can change values as well as negative stereotypes, representations, and perceptions about old age. Yet, intergenerational activities are inadequate from the perspective adopted in this analysis. Meetings between children and retirees, rather than being inclusive measures, infantilize the elderly by placing them at the same level as children, in forced environments controlled by younger adults.

Priority 7 is to facilitate intergenerational contact as a form of natural life relationship, making spaces and planning programs that appeal to everyone (younger and older generations). In return, senior universities concentrate most educational activities for the elderly, such as schooling and Information and communication technology programs. This creates barriers to intergenerational contacts, does not ensure transport for the most isolated or economic security for the most disadvantaged people, and can become elitist spaces. In practice, the users of senior universities are those who enjoy the other local programs. It suggests an information system addicted to channelling activities to only one group. These criticisms reinforce priorities 3 and 5. 
Housing plays a key role in the elderly's quality of life and health because they are used to spending much of their time at home (Keyes et al., 2014); the majority of them value their independence and prefer to continue to live in their own homes (Eurostat, 2016). Aging in the home requires housing units that are adaptable to people's needs as they age, able to accommodate a growing variety of lifestyles (Keyes et al., 2014). In Portugal, it is still necessary to combat the deep housing vulnerability with which a large part of the population lives, which is a poverty and social exclusion indicator. The housing comfort improvement program (3.6) had the lowest score in Coruche. Despite providing decent housing, including construction materials distribution for specific reconstructions and home adaptation, this measure is targeted at poor people with complex dependency needs. The elderly who are at risk for decreasing mobility at home do not constitute the target group of this measure. The requalification of historic centers program (3.2) had the lowest score in Oeiras, since it is only concerned with urban centers, remembering that, according to priority 6 , we should pay special attention to the most geographically or socially isolated citizens, the most fragile, and those with health problems.

The active aging perspective calls for the development of measures to improve physical, mental, and social health. There is a trend toward relocation of public health responsibility from the health authorities to the local authorities. Local authorities take a leading role in the development and implementation of community-based approaches aimed at health promotion and disease prevention and focused on chronic problems and compressing disability into a shorter period of time at the end of life (Olshansky et al., 2011). In Coruche, the program with the lowest score was the transportation and follow-up of treatment and medical consultations (3.6). It offers transportation and accompaniment to disadvantaged members of population for attending hospital treatments and medical consultations. However, it is an incipient policy, since it is only able to respond to some patients in the psychiatric field. The application of priority 1, by entering into partnerships with other local organizations and businesses, would improve the measure. Priority 6 should also be taken into account, including people with several disabilities as well as the isolated elderly.

If longevity is accompanied by a higher probability of chronic diseases, the elderly are likely to live in polymorphism conditions. Under these circumstances, the elderly are also major consumers of medication. Nevertheless, medications co-payment (3.6) has the lowest value in the health category in Oeiras, since it only addresses economic accessibility, being directed to the most disadvantaged sections of the population older than 65. In fact, there are high rates of medication problems among elderly patients with chronic conditions (Fiavolá et al., 2005), and economic accessibility is just one of them. Other problems are not considered, such as (1) inappropriate use of 
medication, (2) use of more drugs than are needed, (3) the elderly consulting various different medical doctors and not informing the family doctor about the medicines prescribed by other specialists, and (4) self-medication (Waszyk-Nowaczyk, Blaszczyk, Michalak, \& Simon, 2016). Having said that, priority 1 suggests that the collaboration with pharmacies and local health and social services will support people and solve several medication problems.

Safety is one of the active aging pillars and is described by ILC-BR (2015) as the most fundamental of human needs. Through these approaches, security must be viewed from a broad perspective including physical, social, financial, and cultural issues (concerning the preservation of cultural identity). An aging society requires security policies focused on the right to basic security and dignity of all persons. We refer to education, health, and housing quality; measures such as injury prevention, promotion of environmental quality, and practice of physical activity (Collins \& Hayes, 2010); and also crime reduction, discrimination and violence prevention, decreasing economic inequalities, decent work for people of all ages, and poverty eradication (ILC-BR, 2015). In the safety category, only one program, named seniors in security (3.8), was analyzed. It is a partnership between Oeiras local government and public security police, conducting enlightenment sessions and promoting physical, economic, and psychological security. Even so, this program was an area subject to much criticism, as it is uniquely directed toward older people, strengthening the conflict with priority 5 .

Priority 8 is to promote security from a holistic perspective, in all policy sectors. The increase in longevity disrupts the organization of the life cycle in the following three ways: (1) training, (2) activity, and (3) reform (Fernandes, 2016), due to the late entry of young people into the labor market, which is a consequence of the extended time devoted to education and precariousness at the beginning of employment. On the opposite side, in the developed countries there is a trend to reducing the activity of workers aged 55 to 64 as well as to excluding the elderly from the labor market (elderly have also difficulties in maintaining their jobs; Fernandes, 2008). In fact, this theme requires the development of strategies that enable, encourage, and facilitate an active life as a right of the elderly. The maintenance and inclusion of older workers in the labor market, as well as their involvement in civic participation activities such as volunteering, allow them to continue to contribute to their communities after retirement. Both territorial units presented the same program in the labor sector: local volunteer bank (3.5), which is a branch of the national volunteer bank. However, in Coruche, the program does not have volunteers aged 65 or older and the elderly benefited only as recipients of volunteer work.

Priority 9 is to create labor opportunities for the elderly; to stimulate the adaptation of work conditions as people age; and to promote the elderly's 
participation in formal and informal activities, focusing on diversity, accessibility, awareness, encouragement, and integration of different generations and cultures, as well as information and communication (Fitzgerald \& Caro, 2014; WHO, 2007).

When older adults can no longer drive a car, alternative transportation is of major interest. The transportation sector has a strong impact on other intervention categories if we consider that it constitutes the privileged way to access health, social, recreational, and cultural services. Regarding transportation programs, the road plans within the urban perimeters had the lowest score in Coruche (3.4). These vehicles circulate frequently during school periods (mainly useful for students) but are very scarce on holidays. It does not meet the needs of elderly persons living in small villages farthest from the urban center. The only program analyzed in Oeiras, adapted transport service, had a high score (4.2). It facilitates disabled people's mobility and autonomy in accessing community services, such as educational institutions, physical and socioprofessional rehabilitation services, and cultural and leisure opportunities.

Mobility management, vehicles' user-friendliness, and economic accessibility could improve elderly participation (Lehning, 2014). Local governments of the selected municipalities are concerned with controlling the traffic speed and improving roads and visibility of road marking, physical space accessibility, walkways, and traffic light systems. Community organizations and transport sector companies can also take a wider range of steps recommended by the literature, such as (1) improving transport comfort; (2) education, awareness, and evaluation of drivers regarding caring for passengers with disabilities or movement limitations; (3) information accessibility, such as by increasing the letter size on signs and destination/schedules/stops indications; (4) intersection simplification; and (5) provision of and copayment for private transport services when used by the disadvantaged elderly to travel to relevant destinations, such as medical treatments.

Priority 10 is to improve the transport network, especially in remote areas far from urban centers, making it fast, frequent, and accessible with circuits that cover essential consumer and participation services and social and health resources. This priority also comprises investing in public transport information, developing partnerships with private companies, and conducting training and awareness sessions for drivers.

\section{Limitations}

This study served as a pilot study of the application of the MALPA instrument to determine priorities and facilitate the development of guidelines. Although the instrument fulfilled the proposed objective, reducing subjectivity in the evaluation of aging policies, we identified limitations to the research. The evaluation and analysis of aging policies are faced with difficulties intrinsic to the 
heterogeneity in the operation of the model, taking into account the different types of applicators (researcher, policy makers, or other stakeholders). In addition, some authors point out that the implementation and evaluation of such programs are long term and therefore highly complex (Caprara et al., 2013). Thus, we recognize that the model needs to be tested in more and different realities because we need to understand the level of acceptance or rejection of the instrument by the stakeholders. In addition, we note that the instrument may have limitations when applied to a highly heterogeneous population, which presents significant complexity in policy design, analysis, and evaluation.

\section{Conclusions}

In this study, we adopted a critical sense that highlights the lower values obtained with MALPA, considering them the most inadequate programs and establishing guidelines for their improvement and adequacy to the active aging perspective. However, we recognize the efforts of local organizations, which are revealing of the level of concern for and knowledge of the many challenges posed by an aging population. In addition, collaboration with the present research demonstrates openness to governance by local governments.

Although, more and more, we are betting on a holistic vision that characterizes active aging, recognizing a prospect of change in relation to old age, its potential has not been sufficiently understood by the politicians who lead its implementation. The results of this research prove that, in the two analyzed units, the policy instruments do not correspond to the scope of the paradigm. The MALPA application allowed us to identify the lower scores as intervention priorities in the territorial units analyzed. In general, the priorities apply to both territorial units and may be reflected by other territories. The selection of two distinct municipalities, as a pretension of comparing contexts, resulted in guidelines capable of being transported to different regions. However, MALPA needs to be tested in these different realities.

Although we have taken into account the socioeconomic and demographic conditions of the population, as well as the life conditions linked to a particular kind of lifestyle (urban in Oeiras and rural in Coruche), we believe that these results should be complemented with the characteristics of the population, in terms of needs, wishes, and expectations, in order to define priorities.

\section{Funding}

This research was funded by the Interdisciplinary Centre of Social Sciences-CICS.NOVAFCSH/UNL, UID/SOC/04647/2013, with the financial support of the Foundation for Science and Technology Portugal-FCT/MEC through national funds. 


\section{ORCID}

Maria João Bárrios (D) http://orcid.org/0000-0002-4569-9770

Ana Alexandre Fernandes (i) http://orcid.org/0000-0002-7686-3932

António Manuel Fonseca (D) http://orcid.org/0000-0002-9087-1306

\section{References}

Almeida, M. (2009). Promoção da Saúde depois dos 65 anos: Elementos para uma política integrada de envelhecimento ( $\mathrm{PhD}$ Thesis). Escola Nacional de Saúde Pública da Universidade Novade Lisboa, Lisboa, Portugal.

Barbosa, C., Feio, P., Fernandes, A., \& Thorslund, M. (2016). Governance strategies to an aging society-local role in multi level processes. Journal of Comparative Politics, 9(1), 4-18.

Bárrios, M. J. (2017). Políticas de Envelhecimento ao Nível Local. Análise e Avaliação de Programas a Partir do Paradigma de Envelhecimento Ativo (PhD Thesis). Univerity of Lisbon, Lisbon, Portugal.

Bárrios, M. J., \& Fernandes, A. A. (2014). A promoção do envelhecimento ativo ao nível local. Análise de programas de intervenção autárquica. Revista Nacional De Saúde Pública, 32(2), 188-196.

Bárrios, M. J., \& Fernandes, A. A. (2015). Local promotion of active aging: Community support and well-being of people 65+. The International Journal of Aging and Society, 5(4), 23-32. doi:10.18848/2160-1909/CGP

Bernhard, I. (2013). E-government and E-governance-Swedish case studies with focus on the local level. KTH architecture and the built environment. Stockholm, Sweden: University West.

Caprara, M., Molina, M. A., Schettini, R., Santacreu, M., Orosa, T., Mendoza-Núñez, V. M., ... Fernández-Ballesteros, R. (2013). Active aging promotion: Results from the vital aging program. Current Gerontology and Geriatrics Research, 2008, 1-14. doi:10.1155/2013/ 817813

Capucha, L. (2012). Envelhecimento e políticas sociais: Novos desafios aos sistemas de proteção. Proteção contra o risco de velhice: Que risco? In C. Moura (Org.), Processos e estratégias de envelhecimento. Vila Nova de Gaia, Portugal: Euedito.

Collins, P., \& Hayes, M. (2010). The role of urban municipal governments in reducing health inequities: A meta-narrative mapping analysis. International Journal for Equity in Health, 9, 13. doi:10.1186/1475-9276-9-13

Duran, P., \& Thoenig, J. C. (1996). L'État et la gestion publique territorial. Revue Française De Science Politique, 46(4), 580-623. doi:10.3406/rfsp.1996.395082

Esping-Andersen, G. (2009). Três lições sobre o Estado-providência. Lisboa, Portugal: Campo da Comunicação.

Eurostat. (2015). People in the EU: Who are we and how do we live? Luxembourg: Publications Office of the European Union.

Everingham, J., Warburton, J., Cuthill, M., \& Bartlett, H. (2012). Collaborative governance of aging: Challenges for local government in partnering with the seniors' sector. Local Government Studies, 38(2), 161-181. doi:10.1080/03003930.2011.615834

Fernandes, A. A. (2008). Questões Demográficas: Demografia e Sociologia da População. Lisboa, Portugal: Edições Colibri-Faculdade de Ciências Sociais e Humana da UNL.

Fernandes, A. A. (2016). A proteção Social na Velhice estará em Risco? In A. A. Fernandes, P. C. Albuquerque, \& A. M. Fonseca (Eds.), A (re)forma das reformas. Uma análise 
sociológica, económica e psicológica da reforma e do sistema de pensões (pp. 9-53). Lisboa, Portugal: Almedina.

Fialová, D., Topinková, E., Gambassi, G., Finne-Soveri, H., Jónsson, P. V., Carpenter, I., ... Bernabei, R. (2005). Potentially Inappropriate medication use among elderly home care patients in Europe. Journal of American Medical Association, 293(11), 1348-1358. doi:10.1001/jama.293.11.1348

Fitzgerald, K. G., \& Caro, F. G. (2014). An overview of age-friendly cities and communities around the world. Journal of Aging \& Social Policy, 26, 1-18. doi:10.1080/ 08959420.2014 .860786

Fonseca, A., Duarte, D., \& Moreira, S. (2013). Perceções de envelhecimento e regulação do self. Perceptions of aging and self regulation. Revista Eletrónica De Psicologia, Educação E Saúde, 1, 93-117.

Fonseca, A., Teixeira, L., \& Paul, C. (2011). Inventory of Life Satisfaction (ILS): A validation study among Portuguese meddle-aged and older people. Portuguese Journal of Social Science, 10(2), 205-215. doi:10.1386/pjss.10.2.205_1

Fonseca, A. M. (2016). Há vida além da reforma? In A. A. Fernandes, P. C. Albuquerque, \& A. M. Fonseca (Eds.), A (re)forma das reformas. Uma análise sociológica, económica e psicológica da reforma e do sistema de pensões (pp. 91-155). Lisboa, Portugal: Almedina.

Gil, A. (2007). Envelhecimento Ativo: Complementaridades e contradições. Fórum Sociológico, 17, 25-36. doi:10.4000/sociologico.1609

Goerres, A. (2007). Why are older people more likely to vote? the impact of aging on electoral turnout in Europe. Journal Compilation of Political Studies Association, 9, 90-121.

Guillemard, A. M. (1988). Etat et Politique Sociale. Le Cas de la Politique Française de la Veillesse. Les Cahiers De La Recherche Sur Le Travail Social, 15, 115-136.

ILC-BR. (2015). Active aging: A policy framework in response to the longevity revolution (1st ed.). Rio de Janeiro: Brazil: International Longevity Centre Brazil.

INE. (2011). CENSOS 2011 resultados definitivos Portugal. Portugal: Instituto Nacional de Estatística.

Keyes, L., Phillips, D. R., Sterling, E., Manegdeg, T., Kelly, M., Trimble, G., \& Mayerik, C. (2014). Transforming the way we live together: A model to move communities from policy to implementation. Journal of Aging \& Social Policy, 26(1-2), 117-130. doi:10.1080/ 08959420.2014 .854646

Le Galès, P. (2011). Urban governance in Europe: What is governed. In G. Bridge \& S. Watson (Org.), The new Blackwell companion to the city. Oxford, UK: Wiley-Blackwell. doi:10.1002/9781444395105.ch65

Lehning, A. J. (2014). Local and regional governments and age-friendly communities: A case study of the San Francisco Bay Area. Journal of Aging and Social Policy, 26(1-2), 102-116. doi:10.1080/08959420.2014.854140

Lowndes, V., Pratchett, L., \& Stoker, G. (2006). Local political participation: The impact of rules-in-use. Public Administration, 84(3), 539-561. doi:10.1111/padm.2006.84.issue-3

Machado, P. (2004). As malhas que a (c)idade tece. Mudança social, envelhecimento e velhice em meio urbano (PhD Thesis). Lisboa Universidade Nova de Lisboa, Portugal.

Manheimer, R. J. (1998). The promise and politics of older adult education. Research on Aging, 20, 391-414. doi:10.1177/0164027598204002

Menec, V. H., Means, R., Keating, N., Parkhurst, G., \& Eales, J. (2011). Conceptualizing agefriendly communities. Canadian Journal on Aging, 30(3), 479-493. doi:10.1017/ S0714980811000237

Olshansky, S. J., Biggs, S., Achenbaum, W. A., Davison, G. C., Fried, L., Gutman, G., ... Butler, R. (2011). The global agenda council on the aging society: Policy principles. Global Policy, 2, 97-105. doi:10.1111/j.1758-5899.2010.00053.x 
Pierre, J., \& Peters, B. G. (2000). Governance, politics and the state. Basingstoke, Hampshire: Macmillan.

Popescu, L. G. (2013). From a holistic approach of public policy to co-governance. Theoretical and Applied Economics, 7(584), 95-108.

Sallis, J. F., Bauman, A., \& Pratt, M. (1998). Environmental and policy interventions to promote physical activity. American Journal of Preventive Medicine, 15, 379-397. doi:10.1016/S0749-3797(98)00076-2

Stoker, G. (1998). Governance as theory: Five propositions. International Social Science Journal, 50(155), 17-28. doi:10.1111/issj.1998.50.issue-155

Stoker, G. (2011). Was local governance such a good idea? A global comparative perspective. Public Administration, 89(1), 15-31. doi:10.1111/padm.2011.89.issue-1

Waszyk-Nowaczyk, M., Blaszczyk, K., Michalak, M., \& Simon, M. (2016). Pharmaceutical care form application in elderly patients research. Acta Poloniae Pharmaceutica-Drug Research, 73(5), 1375-1380.

World Health Organization (WHO). (2002). Active aging: A policy framework. Geneva, Switzerland.

World Health Organization (WHO). (2007). Global age-friendly cities: A guide. Geneva, Switzerland. 